\title{
FEMALE CHOICE AND THE ADAPTIVE SIGNIFICANCE OF PROLONGED COPULATION IN NEZARA VIRIDULA (HEMIPTERA: PENTATOMIDAE)*
}

\author{
By D. Kelly Mclain \\ Department of Biology, Emory University \\ Atlanta, Georgia 30322
}

\section{INTRODUCTION}

High variance in male reproductive success characterizes male reproductive effort (Bateman, 1948; Trivers, 1972; Wade and Arnold, 1980). This results in strong selection pressures favoring male characteristics which enhance attractiveness or access to females (McCauley and Wade, 1978; Mason, 1980). Selection may also favor mechanisms in males to protect their sperm from displacement by other males from the sperm storage organs of females (Parker, 1970; Waage, 1979a; Ehrlich and Ehrlich, 1978; Zorn and Carlson, 1978). In some species, males guard females from reinsemination (Parker and Smith, 1975; Alcock, 1976; Waage, 1979b). Some species employ prolonged copulation as a means of guarding females (Van Gerwen, et al, 1972; Alcock, 1980).

However, behavior or morphology which appears adaptive in the context of ejaculate competition may have evolved in other contexts (Thornhill, 1980a). Thus, this report analyzes prolonged copulation in the southern green stink bug, Nezara viridula L., in terms of its value in sperm competition and non-reproductive functions. Laboratory studies attempt to determine if social factors mediate the duration of copulation and if the duration of copulation affects the fertilization success of males mating multiply-inseminated females. Field studies are employed to assess the role of prolonged copulation in reducing the level of parasitoidization of males by the tachinid fly, Trichopoda pennipes (F.) at the expense of the female. Laboratory and field data suggest that female $N$. viridula and parasitoids are more frequently attracted to large males. The significance of this preference to $N$. viridula females is also investigated.

Copulation duration in $N$. viridula is highly variable, ranging

*Manuscript received by the editor April 15, 1981 
from $5 \mathrm{~min}$ to $14 \mathrm{~d}$ (Mitchell and Mau, 1969; Harris and Todd, 1980a). Frequently, females remate immediately after the termination of one copulation, but the time between copulations is variable (Harris and Todd, 1980a). The resulting pattern of sperm precedence is atypical for insects because the sperm of the first male to mate the female predominates in the fertilization of the first 2 egg masses following remating, after which the second male gains precedence (McLain, 1981). Egg masses containing 60-120 eggs are laid approximately weekly throughout the 2 month life of the female. A single insemination provides sufficient sperm for fertilization of all the eggs a female produces.

Male $N$. viridula produce a pheromone which attracts females, other males, and the tachinid parasitoid (Harris and Todd, 1980b; Mitchell and Mau, 1971). Parasitoidization by $T$. pennipes greatly reduces $N$. viridula fitness. The lifetime of the parasitoidized stink bug is reduced by greater than $50 \%$ and fecundity, number of eggs per mass, by $40-47 \%$ (Shahjahan, 1968).

\section{Methods}

Two experiments were conducted to determine if the duration of copulation influences male fertilization success. First, 16 yellow colored females were mated in succession to a green male and then to a yellow male. Yellow color is inherited as a simple mendelian recessive trait. Eggs fertilized by yellow males produce red nymphs while eggs fertilized by green males produce black nymphs. Second, 16 yellow females were mated 3 times. Either the first 2 matings were performed by green males or the last 2 by yellow males. This experiment would simulate prolonged copulation if the amount of sperm transferred correlates with the duration of copulation.

Yellow $N$. viridula were provided by Dr. R. I. Sailer from a labortory stock while green adults were the first laboratory generation of field collected adults.

Previous work indicated that the sperm from yellow and green males is equally competitive (McLain, 1981). Therefore, it was not necessary to alternate between the color type of the male inseminating the female first as a control measure. And, employing a green male first would allow detection of males which contained a recessive color allele by inspecting the progeny from eggs laid prior to the second and third matings. This procedure was preferred since 
several rare yellow morphs have recently been discovered in Tifton, Ga not far from Cordele where the present stock was collected (V. Harris, personal comm.).

The sperm precedence experiments employed 7-10 day old virgin males and females. Single females were placed in mason jars with 5 males until mating had begun. The mating pair was removed to a separate jar. Upon termination of mating the sequence was repeated. All bugs were fed fresh green beans. A 16L:8D photophase was used.

The impact of the social environment on the duration of copulation was assessed by determining the duration of copulation for stink bugs exposed to 2 different sex ratios. Jars housed either 4 males and 2 females $(n=79)$ or 2 males and 4 females $(n=40)$. Upon mating, pairs were isolated into separate jars. Pairs were checked 3 times daily, during the $1 \mathrm{st}$, 9th, and 16th hours of the $16 \mathrm{~h}$ photophase. This routine is sufficient to record the great majority of matings since the duration of copulation is rarely less than $8 \mathrm{~h}$ (Harris and Todd, 1980a).

Once matings had terminated, females were isolated and oviposition recorded. The number of fertilized eggs and the hatching percentage were recorded. The size of the mating male was also recorded.

During field collections the number of parasitoid eggs on mating and non-mating males was recorded. The maximum width of the pronotum was also measured, using a hand held ruler. This was to determine if larger males suffered greater levels of parasitoidization. Pronotal width correlates well with male dry weight $\left(\mathrm{r}^{2}=.62\right)$.

To determine if females risk parasitoidization by $T$. pennipes while mating, non-mating females were collected on 5 occasions in August, 1980 from 2 abandoned 5 hectares snap bean fields in Cordele, Ga. The number of parasitoid eggs on each female was recorded. Females were taken to the laboratory and placed singly in mason jars with fresh green beans. Oviposition during the 10 days following collection was recorded.

\section{RESULTS}

The duration of the 1st copulation of females multiply-inseminated correlated with the fertilization success of the males. When the duration of the first copulation was greater than $3.67 \mathrm{~d}$, the first 


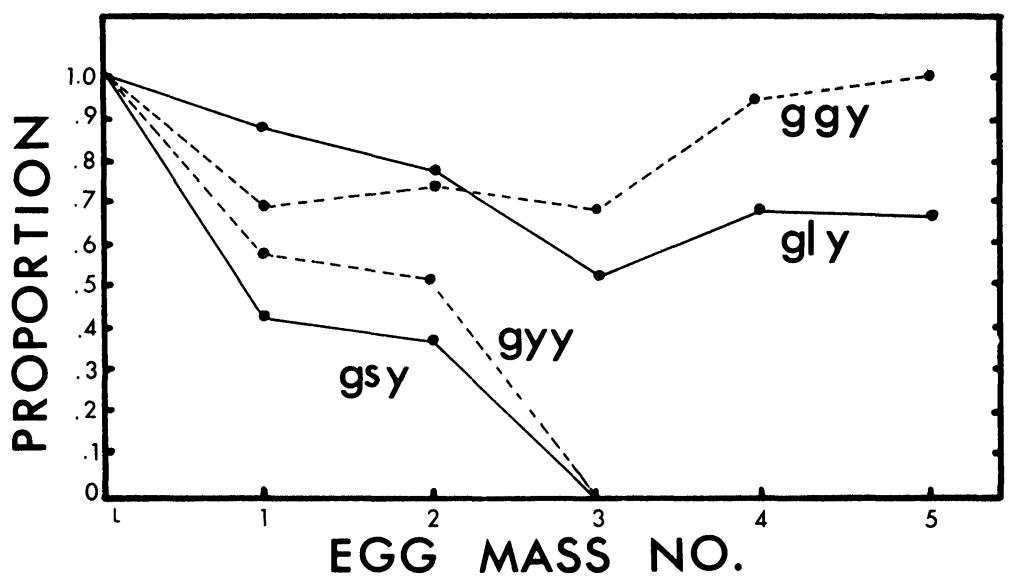

Figure 1. Proportion of eggs fertilized by green males subsequent to the final mating. $g$ (green) and y (yellow) refer to the color types of males mating the females. 1 $(>3.67 \mathrm{~d})$ and $\mathrm{s}(<3.67 \mathrm{~d})$ are the durations of the first copulation for females mated twice. Point $L$ on the abscissa refers to eggs laid prior to the last mating of the female.

male fertilized at least $50 \%$ of the eggs laid subsequent to the second insemination (Fig. 1). When the duration of the second copulation was less than $3.67 \mathrm{~d}$, the 2 nd male gained precedence in the fertilization of later egg masses. These results were independent of the duration of the second copulation.

When the female was mated 3 times the 1 st male still predominated in the fertilization of the 1 st egg mass laid subsequent to the 3rd insemination (Fig. 1). This pattern mimicked the sperm precedence pattern for females inseminated twice. However, when the 1 st 2 males mating the female were of the same color type, the 3rd male fertilized few of the eggs laid subsequent to the 3rd insemination. Thus, this pattern mimicked that where the 1 st copulation was of long duration when females were inseminated twice.

The duration of copulation was longer for pairs isolated from jars with 4 males and 2 females than from jars with 4 females and 2 males (Fig. 2).

In the laboratory, females first mated with the largest male in jars with 4 males and 2 females in 43 of 68 instances in which male pronotal widths had been determined. This proportion $(P=.63)$ was significantly greater than the $\mathrm{P}=.25$ expected by chance alone $(\mathrm{P}<$ 


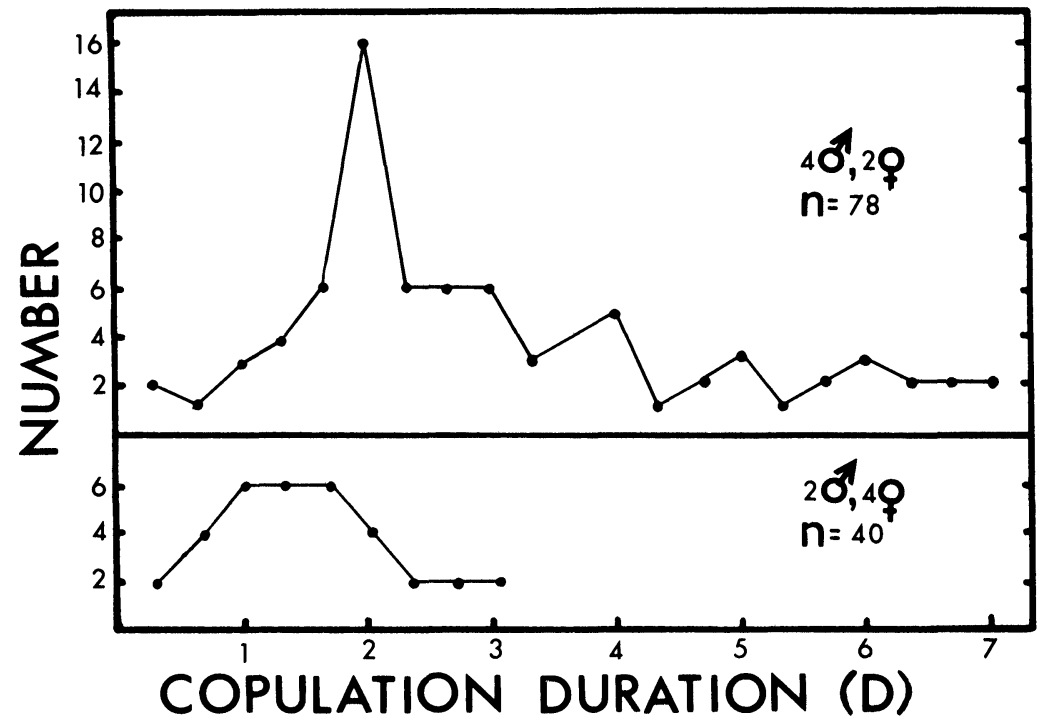

Figure 2. Distribution of mating duration in jars with 4 males and 2 females or 2 males and 4 females. In jars with 4 males and 2 females the proportion of matings greater than the modal duration of $2 \mathrm{~d}$ was significantly greater than the proportion in jars with 2 males and 4 females $(P<.05, t=2.5 ; t$-test $)$.

$.0001 ; \mathrm{t}>5.5)$. Females in the field also tended to mate with larger males (Fig. 3; Table 1). Thus, field and laboratory data indicate that females mate non-randomly with respect to male size.

In the field females might appear to mate non-randomly with respect to size if the duration of copulation were longer for larger males. However, laboratory data suggest that the duration of copulation was not dependent upon male size (Table 1).

Females which mated larger males enjoyed a greater percentage hatching of their fertilized eggs than did females which mated small males (Table 1). This analysis was limited to the second egg mass since the first one often failed to hatch and because failure of hatching in later egg masses might have reflected declining female vigor.

It would be premature to attribute non-random mating solely to female preference. Data collected from jars with 4 males and 2 females indicated that larger males were more viable. Therefore, they may have been more persistent in their mating attempts, more vigorous in intermale aggression, or capable of a more copious 


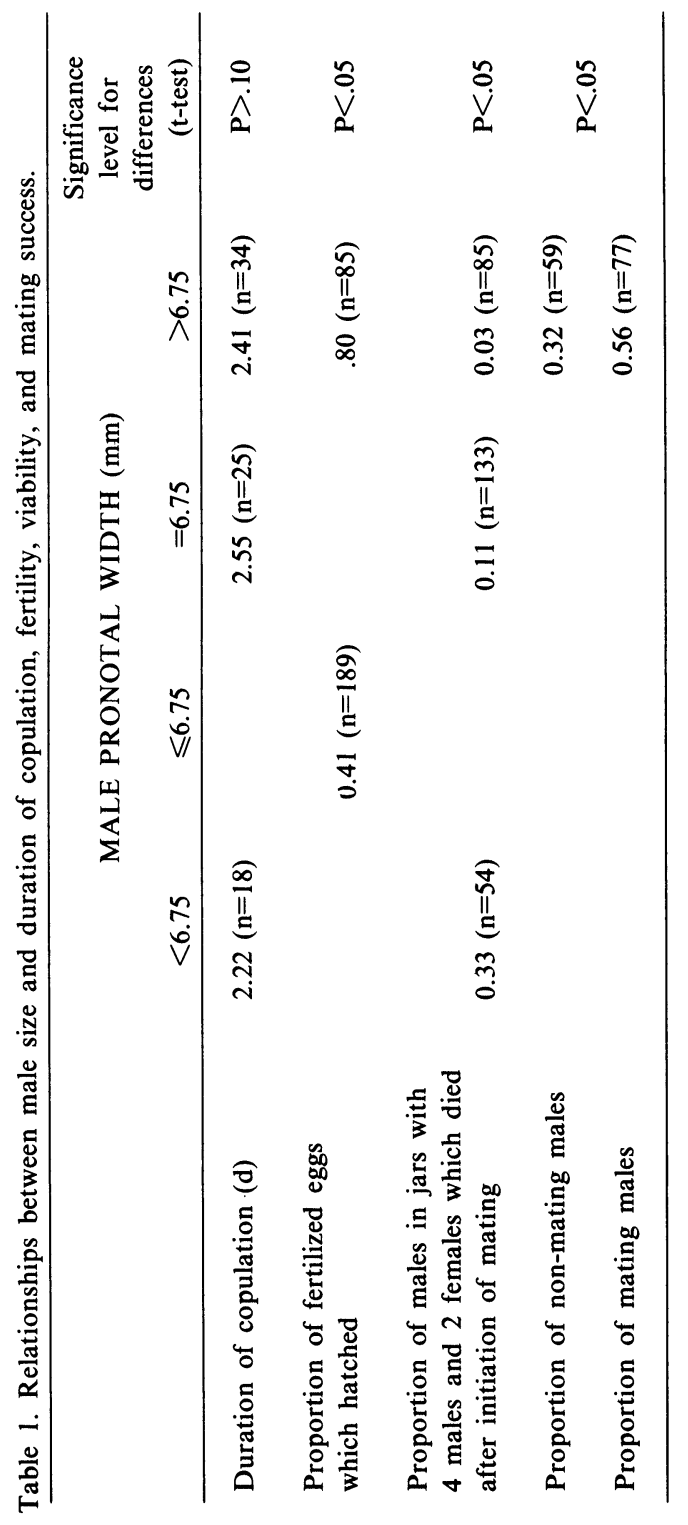


pheromone emission. Upon initiation of mating, the viability of the mating male and the 3 un-mated males was recorded for the $4 \mathrm{~d}$ following. A period of 4 days was chosen as suitable for analysis since $75 \%$ of the matings are less than $4 \mathrm{~d}$ in duration and because analyses based on longer periods of time may not reflect the viability of the males at the time of mating. A significantly greater proportion of males with pronotal widths less than $6.75 \mathrm{~mm}$ died during the $4 \mathrm{~d}$ (Table 1).

The number of parasitoid eggs on field-caught mating males averaged $2.73(n=77$; s.d. $=2.40)$, while the number on males not mating averaged $2.12(\mathrm{n}=59 ;$ s.d. $=1.29)$. The difference between these averages is marginally significant $(.05<\mathrm{P}<.10$; t-test $)$ in spite of the small sample sizes. More intensive sampling might have yielded significant differences indicating that those males which are most attractive to females are also most attractive to the ovipositing parasitoid. A strong relationship existed between male size and the level of parasitoidizaiton (Fig. 4). Thus, both the parasitoid and female $N$. viridula were more frequently attracted to larger males.

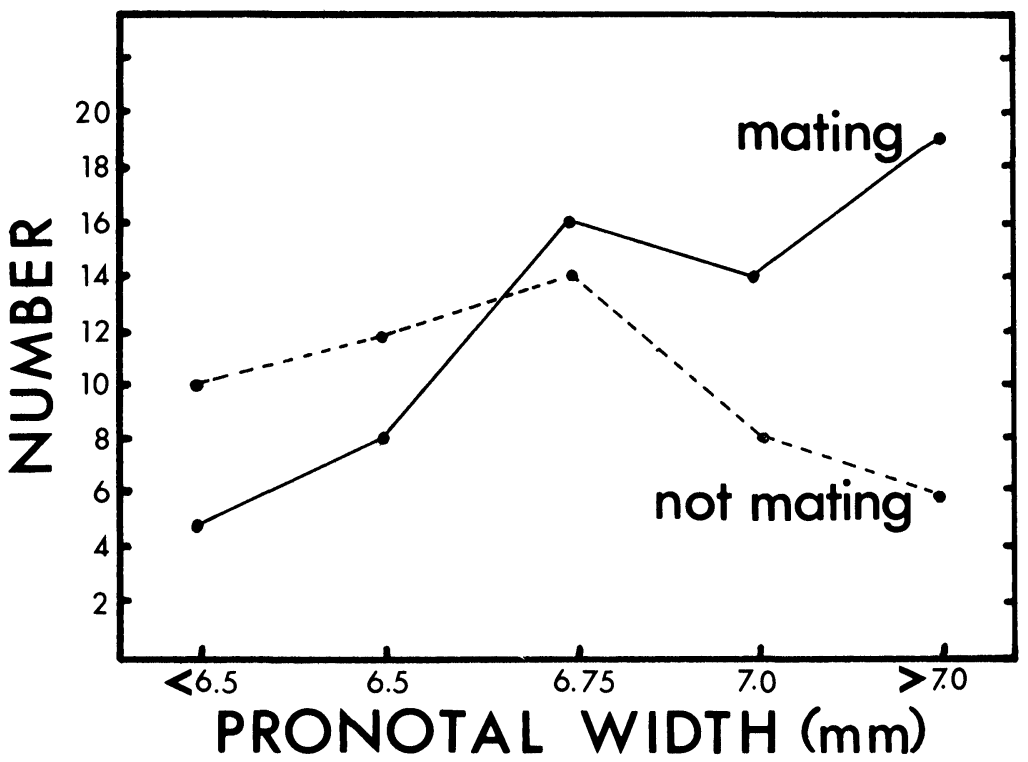

Figure 3. Distribution of male size, pronotal width, in field collected mating and non-mating males. The proportion of mating males with pronotal widths greater than the modal width of $6.75 \mathrm{~mm}$ was significantly greater than the proportion in non-mating males $(\mathrm{P}<.05, \mathrm{t}=2.5$; $\mathrm{t}$-test $)$. 


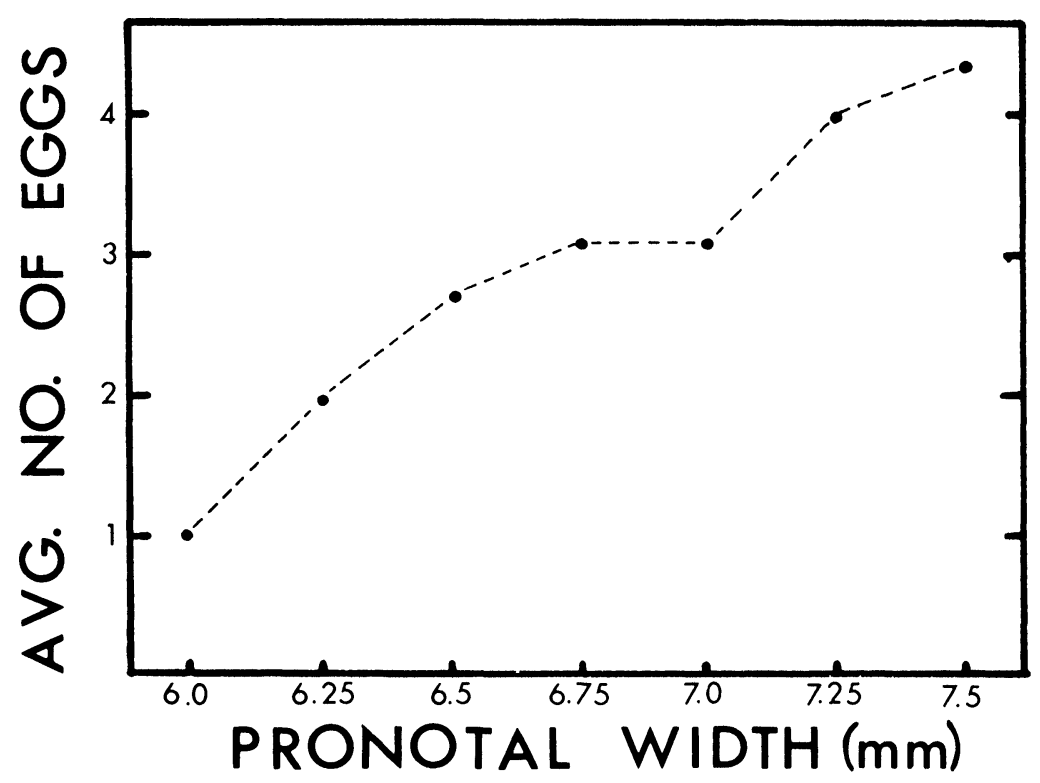

Figure 4. The average number of parasitoid eggs upon males as a function of male size, pronotal width.

Several observations made during the collections in Cordele revealed that non-mating females were attracted to mating males from distances as great as $30 \mathrm{~cm}$. Since the vegetation was dense, this suggests that males continued to emit their pheromone while mating.

Forty-four females not mating at the time of collection had parasitoid eggs upon them. Thirty-one of these females laid fertilized eggs in the laboratory, while only 13 did not. Twenty-seven females not mating at the time of collection had no parasitoid eggs upon them. Only 1 of these females laid fertilized eggs in the laboratory. Thus, a much greater proportion of wild caught females laying eggs in the laboratory had been parasitized than had not $(\mathrm{P}<$ .001 ; t-test for proportions), indicating that mating exposed females to the risk of parasitoidization.

\section{Discussion}

Mating experiments employing yellow and green morphs suggest that long duration of copulation of virgin females enhances male 
fitness by reducing the level of displacement of sperm upon reinsemination of the female. The duration of the second copulation does not influence the degree of sperm displacement. Thus selection may favor longer duration of copulation when males are mating virgins. In fact, when females are mated twice the 1st mating is almost invariably the longer (McLain, 1981). Once-mated females are more likely to oviposit before remating if the first mating is of long duration (McLain, 1981). This could also select for long copulation durations since the 1st egg mass is then laid free from sperm competition.

The duration of copulation is influenced by the social environment. The mating pairs isolated from jars with the greater number of males mated for much longer duration. A similar result was obtained previously by utilizing jars with 9 males and 1 female or 9 females and 1 male (McLain, 1981). However, in the previous experiment the mating pair was not isolated. Since the result did not change with this additional manipulation, the duration of copulation appears in part mediated by the social environment perceived at the initiation of mating as a means of guarding females from other males.

Males may prefer copulations of longer duration to reduce the level of parasitoid infestation they receive at the expense of the female while they contine to broadcast their presence to other females. If the tachinid parasitoid is attracted to an emitting male which is mating, there is a high probability that she will oviposit on the female.

Parasitoidization reduces the fitness of stink bugs because they die when the parasitoid larvae pupate within them. Parasitoidization is also an energetic drain which greatly reduces the energy an adult can allocate to reproductive effort (Shahjahan, 1968).

The genetic interests of the male are better served by parasitoidization of the female rather than additional parasitoidization of himself. The female will probably remate and cease to use the males sperm in later oviposition. Therefore, any future reproductive success the male is afforded must result from his ability to compete for and inseminate other females, an ability which would be greatly compromised by high levels of parasitoidization.

Size may be an important determinant of male fitness (McCauley and Wade, 1978; Thornhill, 1980a). In both the field and the 
laboratory $N$. viridula females and parasitoids interacted more frequently with larger males. Larger males may be more competitive than smaller males in aggressive encounters over females resulting in non-random mating in insects (McCauley and Wade, 1978; Thornhill, 1980b; Alcock, 1979; Hamilton, 1979). Adult $N$. viridula males are very aggressive. Males are frequently observed attempting to dislodge mating pairs.

Alternatively, a large male may be more likely to attract a female if the quantity of pheromone emission is related to male size. The relationship between the level of parasitoidization and male size supports this suggestion.

Since the hatching percentage of fertilized eggs was higher when females had mated larger males, selection may have acted on females to choose larger males even at the increased risk of parasitoidization. It has been suggested that when males contribute nothing but thier gametes to females, as with $N$. viridula, the female chooses males whose genetic contributions to her progeny maximizes her fitness (Borgia, 1979; Lacy, 1979; Walker, 1980). However, it may be doubted that sufficient genetic variation for male fitness characters exists to promote this basis of female choice (Williams, 1975; Powell and Morton, 1979). There is no reason to suspect that larger $N$. viridula males are genetically preferable to smaller males since size in stink bugs often varies greatly with the quality of the diet. Thus, environmental patchiness could contribute to size variation in males. If size has low heritability it may still correlate highly with male health, as indicated by the experimental results. Male health may then correlate with the quantity or viability of the sperm. Therefore, male size may be a suitable criterion for female choice since it may correlate with gamete viability.

This study does not investigate all of the possible selective forces which may promote prolonged copulation. For instance, females may benefit from greater sperm transfer if the sperm or associated proteinaceous secretions could be used as a nutritional source (Mitchell and Mau, 1969; Friedel and Gillot, 1977). Preliminary experiments employing captive toads, Bufo woodhousei, and tethered $N$. viridula indicate that mating bugs are less succeptible to attack than single bugs. Also, predatory attempts on mating stink bugs are less frequently successful than attempts on single bugs. This study does suggest that the behavior, prolonged copulation, which appears adaptive in the context of sperm competition is also adaptive in other contexts. 


\section{Literature Cited}

ALCock, J.

1976. Courtship and Mating in Hippomelas planicosta (Coleoptera; Buprestidae). Coleopt. Bull. 30: 343-348.

1979. The Behavioral Consequences of Size Variation among Males of the Territorial Wasp Hemipepsis ustulata (Hymenoptera: Pompilidae). Behaviour 71: 332-335.

1980. Natural Selection and the Mating Systems of Solitary Bees. Am. Sci. 68: 148-153.

Bateman, A. J.

1948. Intra-Sexual Selection in Drosophila. Heredity 2: 349-368.

BORGIA, G.

1979. Sexual Selection and the Evolution of Mating Systems, in: Sexual Selection and Reproductive Competition in Insects, Academic Press. New York, 19-80.

Ehrlich, A. H. AND P. R. ERLich

1978. Reproductive Strategies in Butterflies: I. Mating Frequency, Plugging, and Egg Number. J. Kans. Entomol. Soc. 51: 666-697.

Friedel, T. and C. G. Gillot

1977. Contribution of Male Produced Proteins to Vitellogenesis in Melanoplus sanguinipes. J. Insect Physiol. 23: 145-148.

Hamilton, W. D.

1979. Wingless and Fighting Males in Fig Wasps and other Insects, in: Sexual Selection and Reproductive Competition in Insects, Academic Press. New York, 167-220.

Harris, V. E. AND J. W. Todd

1980. Temporal and Numerical Patterns of Reproductive Behavior in the Southern Green Stink Bug, Nezara viridula (L.) (Hemiptera: Pentatomidae). Entomol. Exper. et Appl: (in press)

1980. Male Mediated Aggregation of Male, Female, and Fifth Instar Southern Green Stink Bugs and Concomitant Attraction of a Tachinid Parasite, Trichopoda pennipes (F.). Entomol. Exper. et Appl. 27: 1-10.

LACY, R. C.

1979. Adaptiveness of Rare Male Mating Advantage under Heterosis. Behav. Genetics 9: 51-53.

MASON, L. G.

1980. Sexual Selection and the Evolution of Pair-Bonding in Soldier Beetles. Evolution 34: 174-180.

McCauley, D. E. AND M. J. Wade

1978. Female Choice and the Mating Structure of a Natural Population of the Soldier Beetle, Chauliognathus pennsylvanicas. Evolution 32: 771-775.

MCLain, D. K.

1981. Sperm Precedence and Prolonged Copulation in the Southern Green Stink Bug. J. Ga. Entomol. Soc. 16: 70-76.

Mitchell, W. C. AND R. F. L. MaU

1969. Sexual Activity and Longevity in the Southern Green Stink Bug, Nezara viridula. Ann. Entomol. Soc. Am. 62: 1246- 1248. 
1971. Response of the Southern Green Stink Bug and its Parasite, Trichopoda pennipes, to Male Stink Bug Pheromones. J. Econ. Entomol. 64: $856-859$.

PARKer, G. A.

1970. Sperm Competition and its Evolutionary Consequences in the Insects, Biol. Rev. 45: 525-568.

Parker, G. A. AND J. L. Smith

1975. Sperm Competition and the Evolution of the Precopulatory Passive Phase in Locusta migratoria migratorioides, J. Entomol. Ser. A. Gen. Entomol. 49: 155-171.

Powell, J. R. AND L. MoRTon

1979. Inbreeding and Mating Patterns in Drosophila pseudoobscura, Behav. Genetics 9: 425-429.

ShahJahan, M.

1968. Superparisitization of the Southern Green Stink Bug by the Tachinid Parasite Trichopoda pennipes and its Effect on Host Survival, J. Econ. Entomol. 61: 1088-1091.

THORNHILL, R.

1980. Rape in Panorpa Scorpionflies and a General Rape Hypothesis, Anim. Behav. 28: 52-9.

1980. Sexual Selection within Mating Swarms of the Lovebug, Plecia nearctica (Diptera: Bibionidae), Anim. Behav. 28: 405-412.

Trivers, R. L.

1972. Parental Investment and Sexual Selection, in: Sexual Selection and the Descent of Man, Aldine Publ. Co., Chicago, 136-179.

Van Gerwen, A. C. M., L. B. Brown and C. E. Soo Hoo

1972. Factors Affecting the Time of the Crepuscular Mating Flight and Duration of Mating of the Moth Oncopera alboguttata Tindale (Lepidoptera: Hepialidae), J. Aust. Entomol. Soc. 11: 340-343.

W AAGE, J. K.

1979. Dual Function of the Damsel Fly Penis: Sperm Removal and Transfer, Science 203: 916-918.

1979. Adaptive Significance of Post Copulatory Guarding of Mates and Nonmates by Male Calopteryx maculata (Odonata), Behav. Ecol. Sociobiol. 6: 147-154.

Wade, M. J. AND S. J. ARnold

1980. The Intensity of Sexual Selection in Relation to Male Sexual Behavior, Female Choice, and Sperm Precedence, Anim. Behav. 28: 446-461.

WALKER, W. F.

1980. Sperm Utilization Strategies in Non-Social Insects, Am. Nat. 115: 780-799.

Williams, G. C.

1975. Sex and Evolution, Princton University Press, Princeton.

Zorn, L. P., JR. AND A. D. CARLSON

1978. Effect of Mating on the Response of Female Photuris firefly, Anim. Behav. 26: 843-847. 

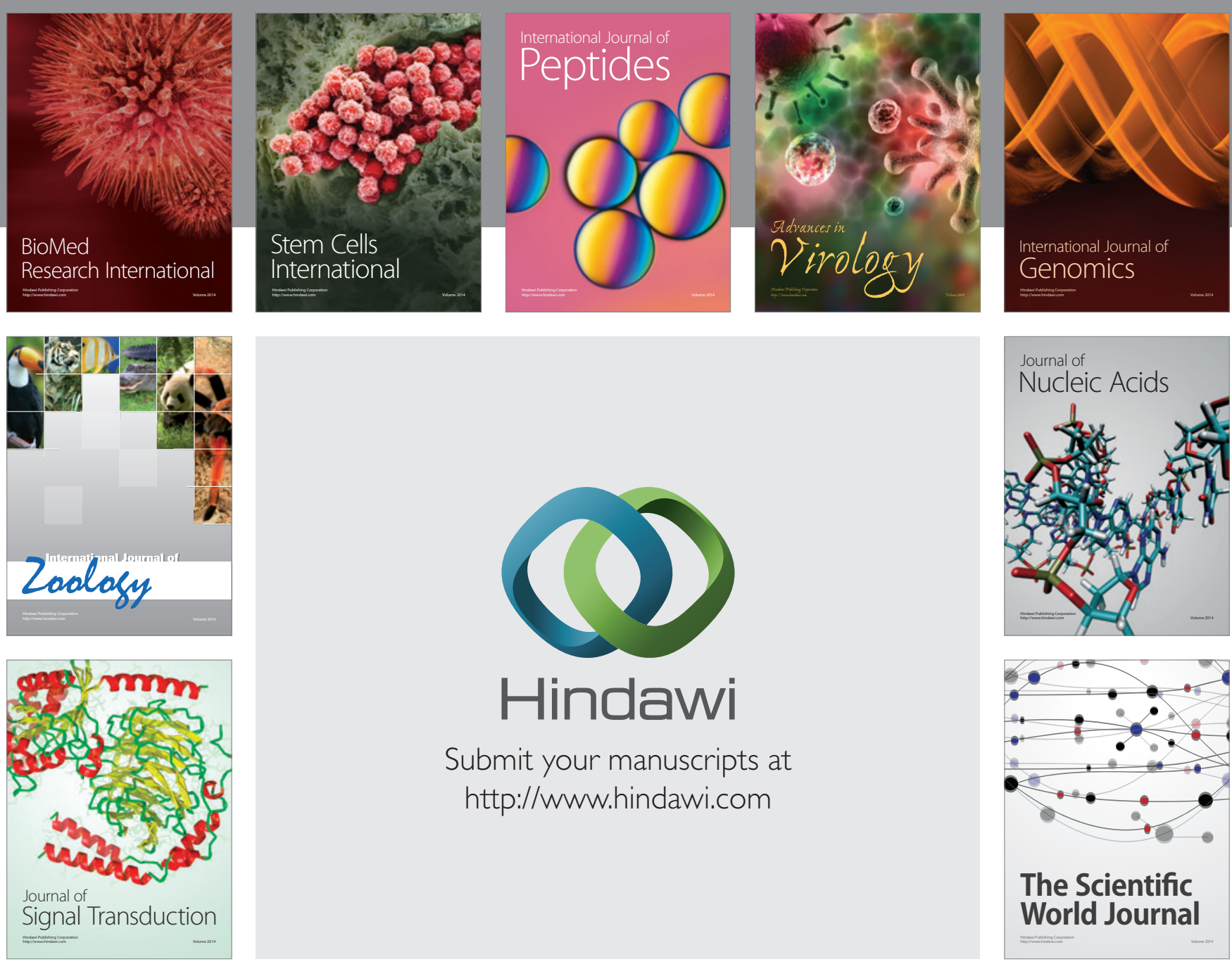

Submit your manuscripts at

http://www.hindawi.com
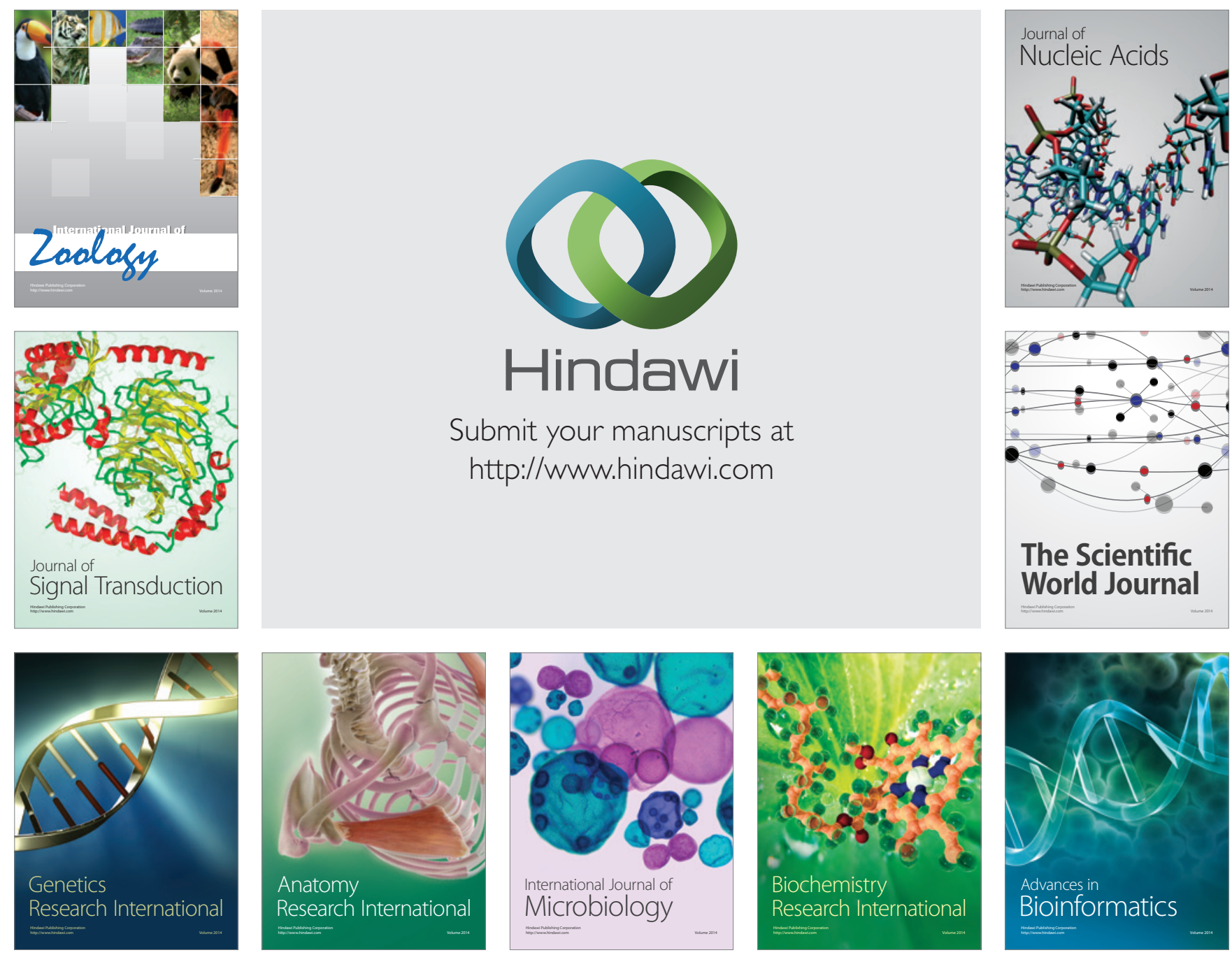

The Scientific World Journal
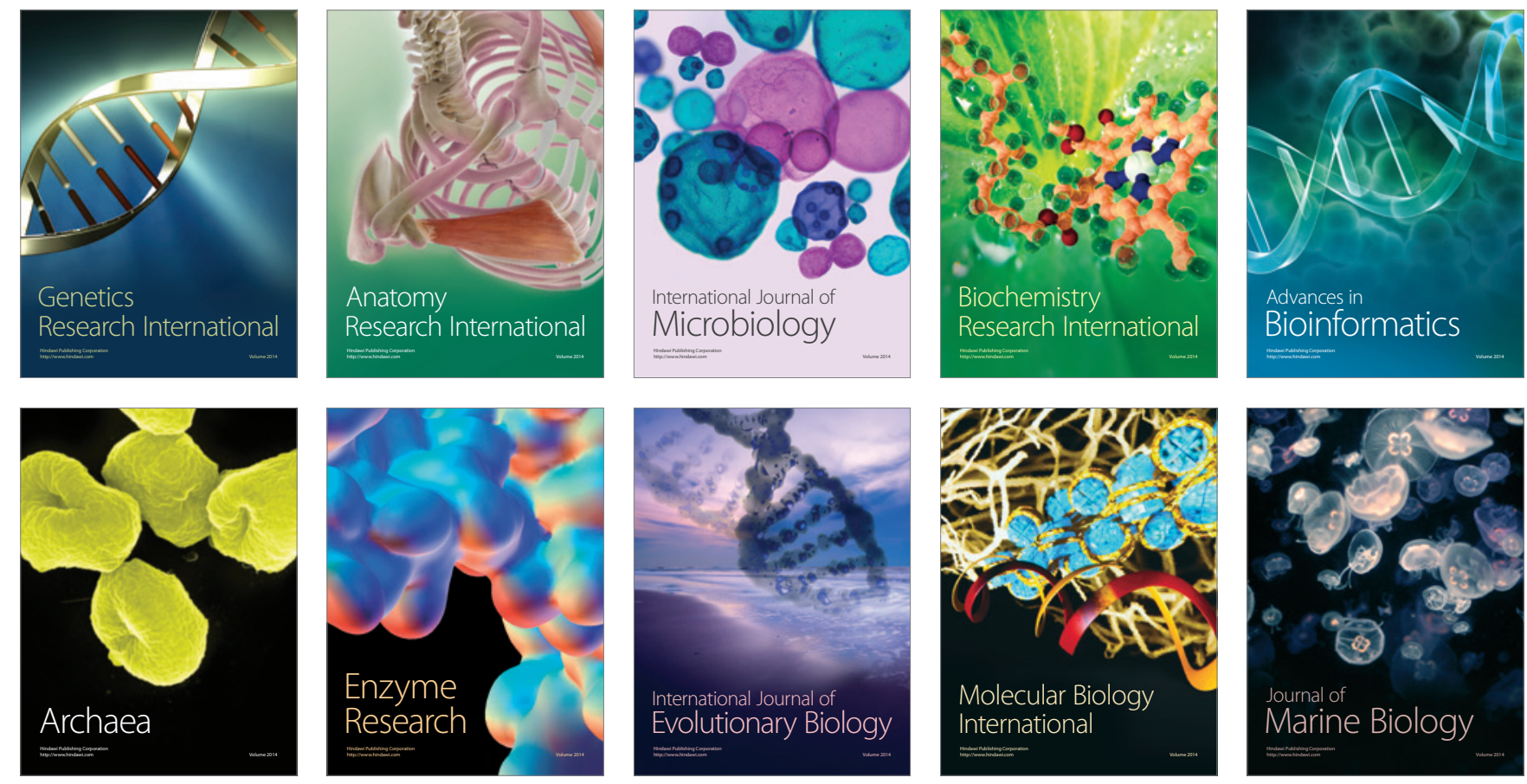